\title{
Lesões do esmalte dental relacionadas aos dentifrícios clareadores
}

\author{
Danilo Barral Araújo ${ }^{1}$ \\ Elisângela de Jesus Campos ${ }^{1}$ \\ Luciana Rodrigues Silva ${ }^{2}$ \\ Roberto Paulo Correia de Araújo ${ }^{3}$
}

\begin{abstract}
Resumo
Diversos estudos têm atribuído aos dentifrícios contendo agentes clareadores o surgimento de lesôes na morfologia do esmalte. Contudo, não existe consenso entre os pesquisadores, quanto à relevância da severidade das lesões detectadas na superfície dental. Objetivo: o presente estudo visa a avaliar, in vitro, os efeitos do peróxido de hidrogênio, do peróxido de carbamida e do bicarbonato de sódio contidos na formulação de dentifrícios sobre o esmalte dental humano. Metodologia: realizado o escurecimento laboratorial, os pré-molares humanos que constituíram a amostra foram escovados com os dentifrícios contendo as duas substâncias clareadoras e o produto abrasivo, sendo determinadas, por espectrofotometria, as colorações dos espécimes, antes e após este procedimento. Através da microscopia eletrônica de varredura (MEV) foram obtidas imagens que analisadas, revelaram a natureza das lesōes surgidas na superfície do esmalte. Resultados: a eficácia clareadora do peróxido de hidrogênio e de carbamida, e o efeito abrasivo do bicarbonato foram constatados, já que os corpos-de-prova tratados retornaram às suas colorações originais. Com base na MEV, a avaliação das superfícies do esmalte submetido aos produtos testados revelou o surgimento de diferentes tipos de lesóes morfológicas de severidades distintas. Conclusão: os dentifrícios clareadores contendo peróxido de hidrogênio e peróxido de carbamida produzem lesōes na superfície do esmalte, sendo que as seqüelas mais acentuadas estão relacionadas ao primeiro.
\end{abstract}

Palavras-chave: Clareamento dental - Peróxido de hidrogênio - Peróxido de carbamida - Lesões morfológicas de esmalte.

\section{INTRODUÇÃO}

O clareamento dental é um procedimento odontológico que cumpre funcionalidade estética, condição que favorece a preservação da auto-estima dos indivíduos, uma vez que devolve aos mesmos a aparência de um sorriso saudável. Este recurso tecnológico destinado a solucionar as alterações de cor das unidades dentais se classifica em extrínseco e intrínseco. O manchamento de origem interna pode surgir nas fases pré e pós-eruptivas em decorrência de excessiva ingestão de determinados medicamentos durante a maturação do germe dental, assim como a alta ingestão de flúor ou tetraciclina na fase pré-eruptiva. O

\footnotetext{
${ }^{1}$ Professor Assistente de Bioquímica Oral. Mestre em Odontologia Instituto de Ciências da Saúde - Universidade Federal da Bahia

${ }^{2}$ Professora Titular de Pediatria. PhD em Medicina

Faculdade de Medicina - Universidade Federal da Bahia.

${ }^{3}$ Professor Associado de Bioquímica Oral. Livre Docente em Odontologia

Instituto de Ciências da Saúde - Universidade Federal da Bahia.

Correspondência para / Correspondence to:

Danilo Barral de Araújo

Instituto de Ciências da Saúde-Universidade Federal da Bahia

Avenida Reitor Miguel Calmon s/n. Vale do Canela

40110-902. Salvador, Bahia, Brasil

Fone: (71) 3283-8891

E-mail: danilobarral81@hotmail.com
} 
manchamento é também resultante de traumas dentais que ocasionam hemorragia interna, independente da manutenção da vitalidade pulpar, ou do processo natural de envelhecimento (KUZ'MINA; KRIKHELI; SMIRNOVA, 2006; RIBEIRO et al., 2006).

O clareamento extrínseco é um procedimento considerado eficaz, apto a restabelecer a estética de dentes escurecidos e a harmonia do sorriso, uma vez que consegue promover a remoção de manchas, com conseqüente alteração de cor, sem acarretar maiores prejuízos ao esmalte dental (NOUR ELDIN et al., 2006).

Tanto o processo de escurecimento, quanto o mecanismo de clareamento, só é possível graças à relativa permeabilidade das estruturas dentais. Logo, quanto maior a penetração da substância clareadora na intimidade da unidade dental, maior será a quantidade de pigmentação que se consegue remover, portanto, melhores resultados estéticos são obtidos (LIMA; ARAÚJO, 2006).

As substâncias clareadoras estão subordinadas à reação bioquímica que desencadeia a ruptura das moléculas pigmentadas que impregnam as estruturas dentais, tornando-as mais leves. Produzem, conseqüentemente, uma significativa redução de intensidade da cor alterada, favorecendo o clareamento da unidade dental que está sendo tratada.

Diversos autores atribuem ao poder oxidante dos agentes clareadores a capacidade de promover a decomposição dos materiais orgânicos pigmentadores mediante a liberação de radicais livres, dentre os quais o oxigênio. Esses radicais por possuírem elétrons desemparelhados em seu nível atômico mais externo têm forte tendência a interagir com outros elétrons em igual condição a fim de estabilizar seus orbitais incompletos (GOO et al., 2004; DIETSCHI; ROSSIER; KREJCI, 2006).

Importantes relatos registram o surgimento de efeitos adversos sobre a estrutura dental (perda de substância) e os tecidos circunvizinhos (irritação e/ou descamação). Tem sido mencionado o surgimento de hipersensibilidade durante ou após o clareamento como sendo o efeito mais freqüente. Este achado levanta a hipótese de que os agentes clareadores uma vez infiltrados nos tecidos dentais são capazes produzir alterações morfológicas na estrutura ou na composição molecular dos mesmos (SPALDING, 2000). Contudo, esta questão ainda é muito controversa, não havendo consenso entre os pesquisadores.

O peróxido de carbamida apresenta eficácia de clareamento e possui maior segurança de uso no que diz respeito ao risco de desmineralização da estrutura dental (COBANKARA, 2004). Esta afirmação é sustentada com base nos produtos resultantes da decomposição desse agente clareador: uréia, amônia, ácido carbônico e peróxido de hidrogênio. $\mathrm{O}$ baixo peso molecular da uréia $(60 \mathrm{~g} / \mathrm{mol})$ favorece sua livre fluidez através do esmalte e da dentina, contribuindo para a elevação do pH do meio (WHITE et al ., 2000; LIZARELLI; MORIYAMA; BAGNATO, 2002).

O clareamento realizado com o peróxido de carbamida a $10 \%$, embora possa causar reações ao tecido pulpar, estas são consideradas leves, uma vez que esta substância parece não alterar a integridade deste tecido, já que os sintomas desaparecem após duas semanas (FUGARO et al., 2004; PASQUINI, 2006).

Os dentifrícios que contêm agentes clareadores em suas formulações encontram respaldo em estudos que afirmam que a provável perda mineral se deve mais ao próprio ato mecânico da escovação que promove o desgaste superficial das unidades dentais favorecendo a ocorrência de erosões e abrasões, do que a ação dos agentes clareadores, propriamente ditos (WORSCHECH et al., 2003; TACHIBANA; BRAGA; SOBRAL, 2006). O principal fator relacionado à degradação da superfície dental parece ser o tempo de exposição do esmalte ao agente clareador e não à concentração deste agente (WORSCHECH et al., 2003; WIEGAND; OTTO; ATTIN, 2004; PINTO et al., 2004).

Diversas alterações observadas na morfologia da estrutura do esmalte estão associadas aos procedimentos clareadores, tais 
como: áreas de depressão, formação de crateras, decapeamentos da estrutura clareada, porosidades superficiais, expansão das estrias incrementais de Retzius, redução dos valores de microdureza e exposição de prismas (MIRANDA et al., 2005). Contudo, este efeito deletério sobre o esmalte parece ser menor nas superfícies tratadas pelo peróxido de carbamida do que pelo peróxido de hidrogênio.

Embora diversos trabalhos registrem a ocorrência de seqüelas na morfologia do esmalte em decorrência da ação de produtos clareadores, outros estudos de igual relevância ressalvam que as lesões produzidas não têm significância clínica, uma vez que podem vir a ser remineralizadas dentro do período de 7 a 14 dias, desde que as superfícies tratadas sejam expostas às condiçóes de controle adequado, como, por exemplo, a aplicação tópica de fluoreto após o procedimento clareador (FREITAS et al., 2002).

O presente estudo visa a contribuir para uma melhor compreensão da natureza e da gravidade de possíveis seqüelas que podem atingir a morfologia da superfície do esmalte dental humano advindas de aplicaçôes de agentes clareadores presentes na formulação de dois cremes dentais, comparativamente à ação de um dentifrício com agente abrasivo, através da análise de eletromicrografias.

\section{MATERIAIS E MÉTODOS}

Vinte e cinco faces vestibulares de prémolares superiores e inferiores de humanos cedidos pelo Banco de Dentes das Faculdades UNIME - Bahia, Brasil, constituíram os 5 grupos de estudo de acordo com as normas e critérios de biossegurança pré-estabelecidos, sendo 3 grupos-teste: GT ${ }_{1}$ (Mentadent peróxido de hidrogênio), $\mathrm{GT}_{2}$ (Rembrandt peróxido de carbamida) e $\mathrm{GT}_{3}$ (Colgate com bicarbonato de sódio), de acordo com o agente químico presente na formulação de cada dentifrício aplicado nas escovações; um grupocontrole negativo - $\mathrm{GC}_{1}$, cujo esmalte foi submetido apenas à escovação com dentifrício sem agente clareador (Colgate Total 12)e um grupo-controle repetitividade - $\mathrm{GDC}_{2}$, cujo esmalte foi submetido ao processo laboratorial de escurecimento e escovado com o dentifrício sem agente clareador. Por se tratar de um estudo duplo cego, procedeu-se à constituição dos 5 grupos de estudo com 5 corpos-de-prova cada um, de forma aleatória, por blocagem.

Os dentes selecionados foram acondicionados em soro fisiológico, renovado a cada 24 h, e mantidos sob refrigeração após os procedimentos de limpeza e remoção de possíveis resíduos de tecidos moles. Seguiu-se, a esse procedimento técnico, a secção das coroas da porção radicular, mediante corte horizontal no sentido vestíbulo-lingual, na área correspondente ao limite amelo-cementário. Os remanescentes coronários foram selados com cola adesiva, seguindo-se a inclusão da face lingual ou palatina em resina ortoftálica (LIMA; ARAÚJO, 2006). Para tanto, na área central de cilindros de PVC de $1 / 2$ polegada foi colocada uma porção de cera "utilidade" com o objetivo de fixar e isolar a face vestibular de cada espécime utilizado nas experimentações, seguindo-se do preenchimento de cada cilindro com resina ortoftálica, o que tornou possível a inclusão das demais faces de cada corpo-de-prova na resina. Após a autopolimerização, foi removida a cera, expondo-se, dessa forma, a face vestibular de cada espécime.

Os corpos-de-prova que constituíram os 3 grupos-teste e o grupo-controle repetitividade foram submetidos ao processo laboratorial de escurecimento, mediante imersão numa mistura constituída de partes iguais de café, chá preto, bebida à base de cola, vinho tinto e tabaco (GOMES, 2005). Concluído o escurecimento, os espécimes foram mantidos, durante 96 horas, à temperatura de $37^{\circ} \mathrm{C}$ e conservados em solução remineralizante. A manutenção diária dos espécimes consistiu em rigoroso controle da temperatura e do $\mathrm{pH}$ do meio no qual foram incubados, e a aplicação de três (3) escovações técnicas diárias (NEVES et al., 2002) com base na seguinte padronização: aplicação de escova dental Oral B, com dentifrício sem agente clareador durante 10 segundos, acoplada a um dinamômetro visando o controle da força de escovação equivalente a 0,2 kgf (LIMA; ARAÚJO, 2006). 
Durante 21 dias, procedeu-se à aplicação dos dentifrícios mediante três escovações técnicas diárias (NEVES et al., 2002) adaptadas às condições experimentais deste trabalho. Uma porção equivalente a $0,4 \mathrm{~g}$ de cada creme dental (BENTLEY; ELLWOOD; DAVIES, 1999) foi adicionada à escova Oral B acoplada ao dinamômetro, sendo aplicado o dentifrício durante 10 segundos em cada corpo-de-prova. A manutenção diária dos espécimes foi realizada através do controle da temperatura e do $\mathrm{pH}$ do meio e a conservação em solução remineralizante.

Concluído o período de 21 dias de clareamento, os corpos-de-prova foram lavados com água destilada e deionizada, secos em estufa a $37^{\circ} \mathrm{C}$ durante 24 horas, e acondicionados, por grupo, em recipientes coletores numerados, visando a assegurar o estudo microscópico duplo cego. Através do equipamento IC-50 Ion Coater - Shimadzu, as faces vestibulares dos corposde-prova foram revestidas por uma fina camada de ouro, com aproximadamente $9 \mathrm{~nm}$ de espessura, de forma a tornar a superfície condutora e passível de emissão de elétrons secundários. A análise das amostras foi realizada através do microscópio eletrônico de varredura Superscan SS-550 - Shimadzu. A área objeto de análise foi a zona média dos espécimes. Para tanto, foram estabelecidos aumentos que variaram de $500 \mathrm{x}$ a $5.000 \mathrm{x}$ a $15 \mathrm{kV}$, com o intuito de permitir a avaliação qualitativa detalhada das superfícies em estudo, com vistas a detectar possíveis alterações morfológicas.

\section{RESULTADOS}

A avaliação das imagens de espécimes do grupo $\mathrm{GC}_{1}$ (Figuras 1A e 1B) revelam a presença marcante de camada aprismática. Observa-se alguma irregularidade na superfície do esmalte acompanhada de eventuais porosidades espalhadas aleatoriamente, assim como a ocorrência de ranhuras, além de artefatos que não têm maior relevância.

As eletromicrografias dos espécimes que constituem o grupo $\mathrm{GC}_{2}$ (Figuras $2 \mathrm{~A}$ e $2 \mathrm{~B}$ ) apresentam regularidade em determinadas áreas da superfície do esmalte, devido a alguma redução da camada aprismática. A irregularidade predominante, que é uma característica própria da camada aprismática, favorece a visualização das regiōes prismáticas e interprismáticas que constituem a estrutura mais interna do esmalte, denominada de camada prismática. Essa visibilidade indica que os prismas permaneceram intactos, conforme pode ser constatado pela preservação da camada interprismática, não havendo, portanto, significativa perda de componentes minerais.

As imagens dos corpos-de-prova escovados com o dentifrício contendo peróxido de hidrogênio $\left(G T_{1}\right.$, ) expressam severas alterações na superfície do esmalte dental (Figuras 3A e 3B) caracterizando expressiva agressão à integridade dos prismas. Essas estruturas, além de perderem quantidade substantiva de material mineralizado, apresentam marcante desfiguração dos padrões de organização. São observadas imagens sugestivas de rigorosa corrosão das áreas alcançadas pelo produto clareador, resultando em relevante comprometimento da integridade da morfologia do esmalte, tanto nas regiōes interprismáticas como nas regióes intraprismáticas, seqüela que acentuou as irregularidades superficiais existentes nessa estrutura. Constata-se, também, um aumento do número de depressões, irregularidades e pontos isolados de decapeamento resultantes da remoção dos limites superficiais da área examinada e do acesso à camada mais mineralizada sugerindo o aprofundamento da desorganização da estrutura inorgânica. Alguns artefatos sem maior significância são observados.

Nas eletromicrografias dos espécimes do grupo $\mathrm{GT}_{2}$ tratados com o dentifrício contendo peróxido de carbamida (Figuras $4 \mathrm{~A}$ e $4 \mathrm{~B}$ ) são constatadas alterações de menor severidade na superfície do esmalte. As seqüelas resultantes dos efeitos lesivos produzidos na morfologia dos corposde-prova desse grupo perante àquelas produzidas nos espécimes do grupo GT 1 são de caráter mais moderado. Nota-se, também, que houve remoção da camada aprismática, com inicial comprometimento dos prismas, já que essas estruturas demonstram perda de definição. É observada, ainda, a presença de porosidades pontuais. 
Figuras $1 \mathrm{~A}$ e 1B. Eletromicrografias da superfície do esmalte tratado com dentifrício sem agente clareador. Magnitude:1.500x e 3.000x.
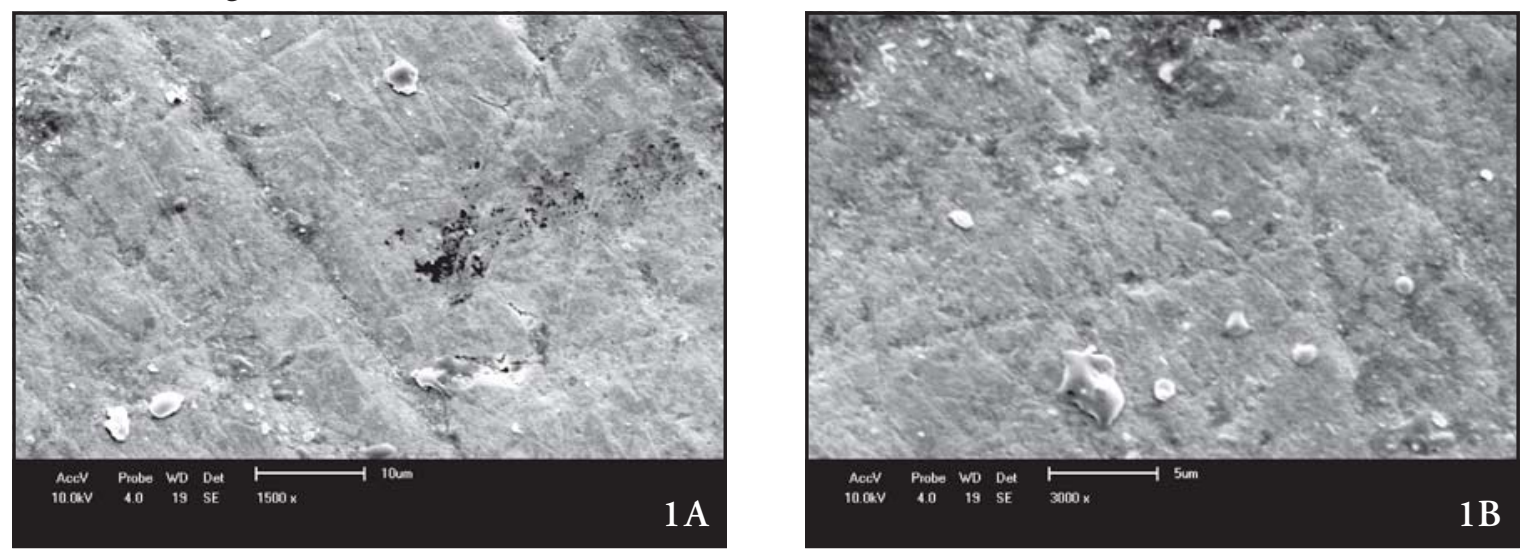

Figuras 2A e 2B. Eletromicrografias da superfície do esmalte escurecido em laboratório e tratado com dentifrício sem agente clareador. Magnitude: 540x.
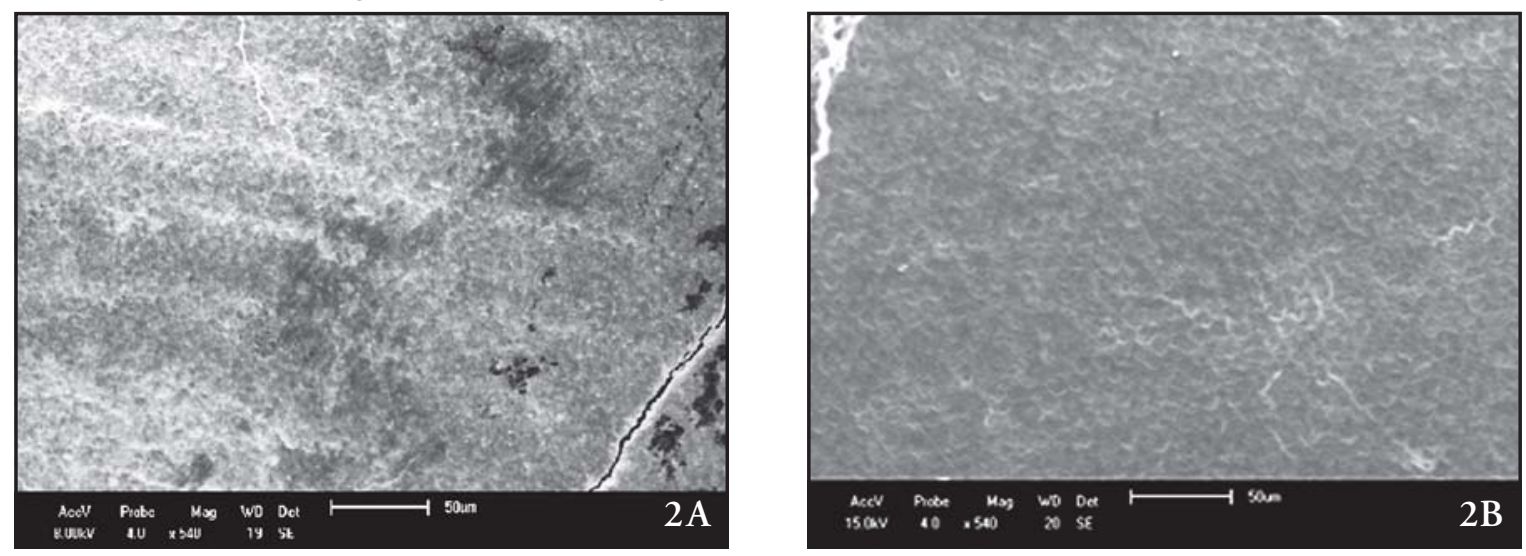

Figuras $3 \mathrm{~A}$ e 3B. Eletromicrografias da superfície do esmalte escurecido em laboratório e tratado com dentifrício contendo peróxido de hidrogênio. Magnitude: 500x e 1.000x.

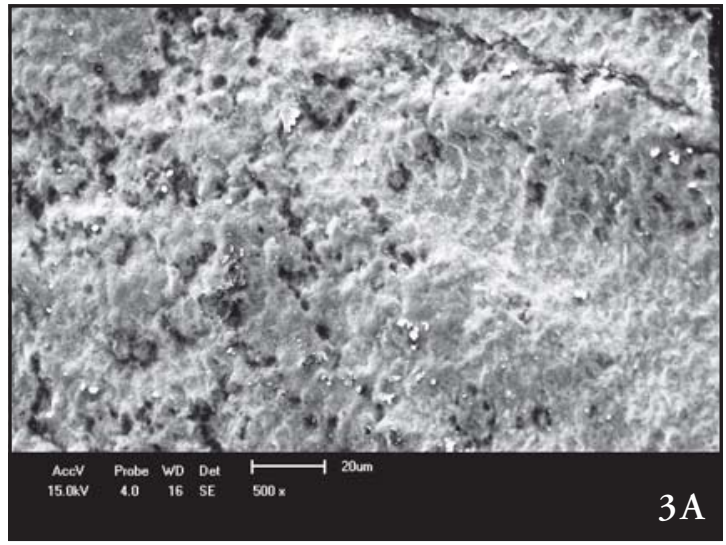

Nas imagens dos corpos-de-prova escovados com o dentifrício contendo o abrasivo bicarbonato de sódio (Figuras 5A e 5B) observa-se que foram as superfícies de esmalte desses espécimes as que apresentaram maior número de áreas afetadas. $\mathrm{O}$

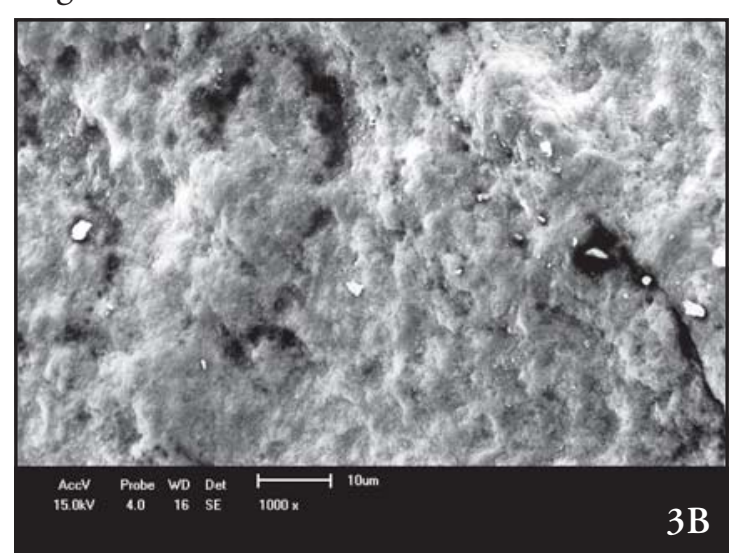

comprometimento morfológico das superfícies é notadamente uniforme e revela a instalação de lesões com maior profundidade. Constata-se uma remoção quase completa da camada aprismática com perda de identidade das regiôes prismáticas, sendo notadas, 
Figuras 4A e 4B. Eletromicrografias da superfície do esmalte escurecido em laboratório e tratado
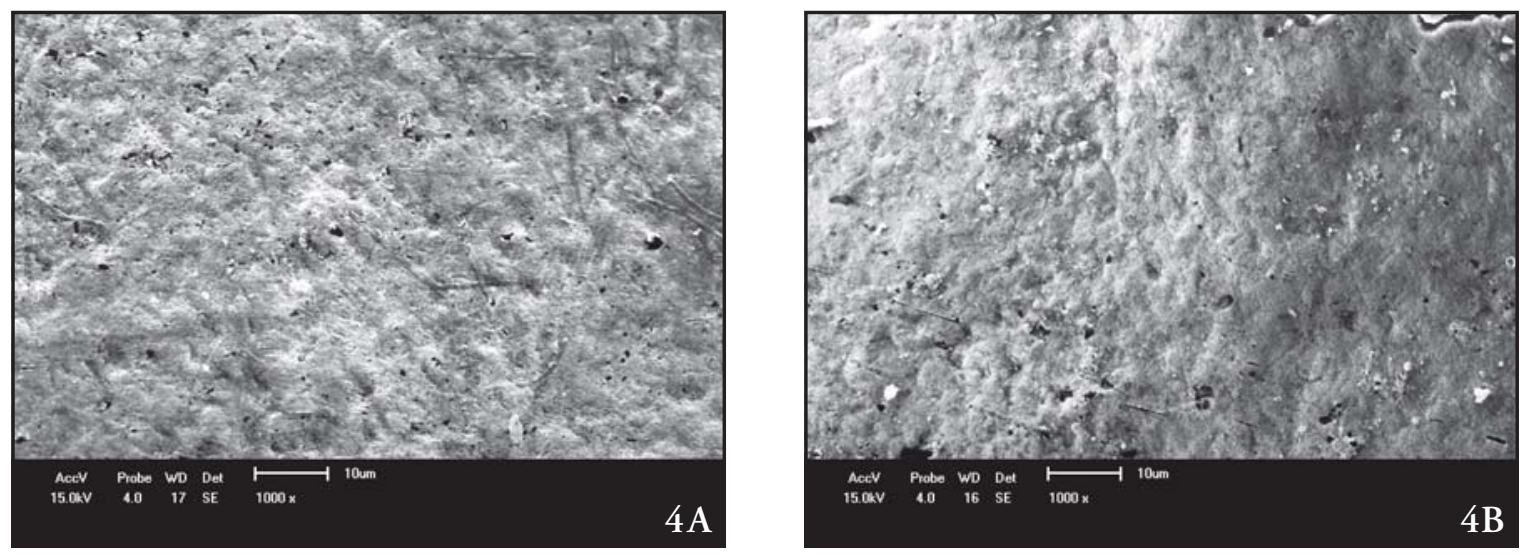

Figuras 5A e 5B. Eletromicrografias da superfície do esmalte escurecido em laboratório e tratado com dentifrício contendo o agente abrasivo bicarbonato de sódio. Magnitude: 700x e 1.000x.

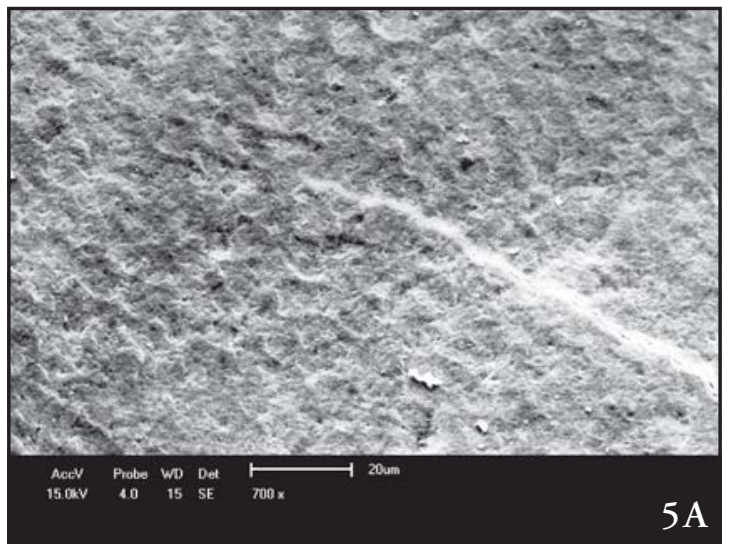

apenas, determinadas regiôes de delimitação dos prismas. Já nas lesóes de severidade marcante não se consegue identificar as prováveis delimitaçôes prismáticas. Em virtude do desgaste das superfícies do esmalte, as imagens resultantes revelam uma aparência porosa e de expressiva regularidade. Todas as áreas examinadas apresentam o mesmo grau de comprometimento, com diminuiçāoo das depressões e irregularidades normalmente vistas no esmalte sadio. Independente da magnitude de cada imagem, a agressão da camada prismática, ao alcançar a intimidade dos prismas, revela perda significativa da estrutura mineral, apresentando um aspecto de pulverização superficial com formação de erosões.

\section{DISCUSSÃO}

As eletromicrografias obtidas além de comprovarem a ocorrência de severas agressões

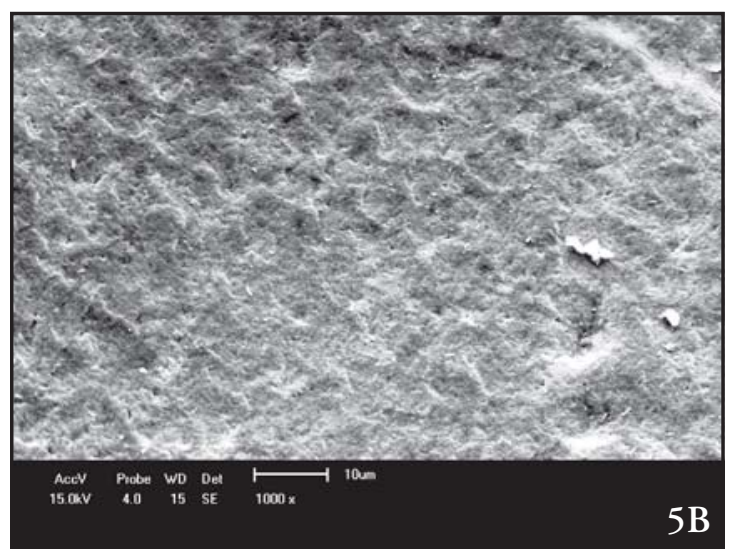

à morfologia da superfície do esmalte contribuem para explicar a origem dos eventos de hipersensibilidade atribuídos ao pósclareamento (SPALDING, 2000; LIZARELLI, 1994). Mesmo reconhecendo que o clareamento é um procedimento técnico de caráter conservador em comparação a outras modalidades de tratamento estético, importantes estudos admitem que a ocorrência da hipersensibilidade que resulta da capacidade de infiltração desses produtos químicos nos tecidos dentais produz alterações morfológicas, estruturais ou de composição molecular.

Com base nos resultados dessa pesquisa, as lesões detectadas após a aplicação dos dentifrícios clareadores têm explicação em diversas causas, dentre as quais a reação de oxidação que ocorre durante o clareamento dental (RIBEIRO et al., 2006; FERREIRA 
ZANDONÁ; ANALOUI; BEISWANGER, 1998), em que pese ser considerada como condição favorável o aumento do $\mathrm{pH}$ do meio pelo peróxido de carbamida. Essa explicação está fundamentada, teoricamente, em estudos que consideram o clareamento dental como um procedimento de natureza química que consiste numa reação de oxirredução, cuja oxidação parcial provoca a ruptura das cadeias carbônicas cíclicas dos compostos pigmentados, tornandoas acíclicas, insaturadas, com duplas ligações, capazes de incorporar hidroxilas, originando produtos com tonalidades mais claras (GOO et al., 2004; DIETSCHI; ROSSIER; KREJCI, 2006). Todavia, admite-se também, que podem surgir decapeamentos da estrutura clareada, devido à perda de material inorgânico desmineralização - frente aos desafios enfrentados pelo esmalte com a queda inicial de pH (PINTO et al., 2004; MIRANDA et al., 2005). Provavelmente, a concentração do peróxido de hidrogênio e do peróxido de carbamida, não informadas, por sinal, pelos fabricantes dos dentifrícios, se configurou numa importante variável causal do surgimento das lesões de esmalte, independente da intensidade, achado esse, compatível com a literatura científica que trata desta matéria (WORSCHECH et al., 2003; WIEGAND; OTTO; ATTIN, 2004; PINTO et al.,2004; CIMILLI; PAMEIJER, 2001; ARAÚJO; TORRES; ARAÚJO, 2006). O fato das lesões resultarem de experimentações realizadas in vitro não minimiza a importância da severidade das mesmas, uma vez que todos os ensaios foram realizados sob rigoroso controle da temperatura e do $\mathrm{pH}$ do meio, da manutenção dos espécimes em saliva artificial, dos cuidados com a técnica de escovação e do atendimento às recomendaçôes de uso dos fabricantes.

A queda do $\mathrm{pH}$ induz a perda de minerais das unidades dentais. Essas perdas tendem a se acentuar seja pelo atrito mecânico produzido pela própria escovação, seja pelas alterações na morfologia do esmalte produzidas pelos agentes clareadores, particularmente, se adicionados aos dentifrícios. Os agentes clareadores que apresentam condições de $\mathrm{pH}$ entre 5.7 e 6.2 podem desencadear desmineralização do esmalte dental ${ }^{2}$.
Nos espécimes do grupo controle $\mathrm{GC}_{1}$ (Figura 1A e 1B) constata-se a presença da camada aprismática, caracterizada pela irregularidade superficial e o aparente caráter de organização. A análise das eletromicrografias revela a ocorrência de eventuais porosidades espalhadas aleatoriamente na superfície do esmalte, além de ranhuras que são consideradas como lesões de natureza leve em função do alargamento das "ranhuras fisiológicas" do esmalte (HUGO et al., 2006). A análise das eletromicrografias do grupo controle $\mathrm{GC}_{2}$ (Figura $2 \mathrm{~A}$ e $2 \mathrm{~B}$ ) sugere ter havido alguma redução da camada aprismática, já que algumas áreas da superfície do esmalte mostraram--se mais organizadas, menos irregulares. Do ponto de vista morfológico, certamente este aspecto é irrelevante já que em várias outras áreas da superfície do esmalte constata-se a presença da camada aprismática. Em que pese o escurecimento laboratorial dos espécimes ser uma condição essencial à determinação da eficácia clareadora das substâncias em estudo e, por conseqüência, das possíveis lesões que venham a ocorrer por conta das substâncias clareadoras, as imagens das áreas prismáticas e interprismáticas que constituem a camada prismática dos corposde-prova do grupo repetitividade $\left(\mathrm{GC}_{2}\right)$ mantêmse íntegras na sua maioria.

Nas eletromicrografias dos espécimes do grupo $\mathrm{GT}_{1}$ (Figuras 3A e 3B) aos quais foi aplicado o dentifrício contendo peróxido de hidrogênio, constata-se severa agressão à superfície de esmalte observada em função da perda dos padrões de organização prismática. As alterações observadas na morfologia do esmalte associadas aos procedimentos clareadores são áreas de depressão, com formação de crateras, comprometimento da microdureza, rugosidade e desgaste da superficial, além da exposição dos prismas nas áreas mais afetadas (MIRANDA et al., 2005; WATANABE et al., 2005; Worschech, 2006; FARAONI-ROMANO; TURSSI; SERRA, 2007; FU; HOTH-HANNING; HANNING, 2007). Áreas de decapeamento da estrutura clareada são sinais de perda de substância inorgânica descalcificação, com desfiguração dos padrões prismáticos em virtude do solapamento de zonas interprismáticas e intraprismáticas acentuando e aprofundando as irregularidades da superfície dental (Figuras 3A e 3B). 
Se a indicação clínica apontar como alternativa para o clareamento dental o peróxido de hidrogênio, essa opção deve recair na concentração de $35 \%$, cuja aplicação é de exclusiva responsabilidade profissional (LIMA; ARAUJO, 2006). Muito embora a concentração dos produtos clareadores incorporados aos dentifrícios deva ser mais baixa, seu uso contínuo em determinado espaço de tempo, mesmo recomendado pelos fabricantes, implica em efeito cumulativo, possibilitando maior agressão química ao esmalte. As lesões observadas no grupo $\mathrm{GT}_{1}$, certamente resultaram da eficácia do peróxido de hidrogênio em penetrar no esmalte, em virtude do seu peso molecular baixo $(34 \mathrm{~g} / \mathrm{mol})$. Essa substância, além de promover a desnaturação de proteínas, propriedade facilitadora do movimento iônico na área em tratamento, favorece a ação clareadora.

De fato houve efetiva mudança na textura superficial do esmalte e no surgimento de depressōes, o que implicou em perda de definição das estrias de Retzius e num aumento de porosidade na estrutura clareada, deixando-a com aspecto semelhante ao efeito causado pelo condicionado parcial com ácido.

As lesôes provocadas pelo peróxido de carbamida (Figuras 4A e 4B) presente na formulação do dentifrício avaliado através dos espécimes do grupo $\mathrm{GT}_{2}$ provavelmente resultaram da desnaturação dos vestígios de proteínas de baixo peso molecular presentes na estrutura orgânica do esmalte. A possibilidade da uréia penetrar na superfície do esmalte e afetar as áreas intraprismáticas e interprismáticas contribui não só para o aumento da permeabilidade do produto, como também para alterar a superfície em nível micro-estrutural (FERREIRA ZANDONÁ; ANALOUI; BEISWANGER, 1998; BASTING, 2005). Embora apresentando lesôes menos acentuadas em comparação àquelas detectadas nos espécimes clareados pelo peróxido de hidrogênio (Figuras 3A e 3B), pôde-se constatar nos corpos-de-prova do grupo teste $\mathrm{GT}_{2}$ a ocorrência de lesões de caráter mais moderado, apesar de ter havido remoção parcial da camada aprismática com comprometimento inicial dos prismas de esmalte, uma vez que essas estruturas exibem alguma perda de definição.
Não se deve perder de vista que apenas o gel de uso caseiro à base de peróxido de carbamida a $10 \%$ é que tem a recomendação da FDA (2007). Esse entendimento torna-se relevante a partir da comparação entre os resultados comprovados nas eletromicrografias dos grupos $\mathrm{GT}_{1}$ e $\mathrm{GT}_{2}$. Constata-se que as lesōes atribuídas ao grupo tratado pelo peróxido de carbamida podem ser classificadas como de menor severidade. Apesar do oxigênio liberado da reação produzida pelo peróxido de carbamida ter a propriedade de aumentar a porosidade $\mathrm{da}$ superfície das estruturas dentais, assegurando melhor penetração e propagação, logo, maior eficácia do agente clareador, e que os radicais livres do oxigênio resultantes da decomposição desse peróxido podem reagir com as estruturas orgânicas dos tecidos dentais favorecendo a perda de minerais (HEGEDUS et al., 1999), o fato do $\mathrm{pH}$ do dentifrício testado se situar em 7.5 se constituiu num fator favorável à menor agressão à estrutura morfológica do esmalte.

Os corpos-de-prova do grupo tratado pelo dentifrício com bicarbonato de sódio $\left(\mathrm{GT}_{3}\right)$ revelou severo comprometimento morfológico e maior profundidade das lesões detectadas, por conseguinte, maior número maior de áreas afetadas. A interpretação das imagens que constituem as Figuras 5A e 5B indica perda acentuada da camada aprismática, comprometimento da identidade das regiōes de prismas de esmalte e aparência porosa com expressiva regularidade. A agressão da camada prismática devido ao alcance da intimidade dos prismas denota uma perda significativa da estrutura mineral, configurando um aspecto de pulverização superficial, com formação de erosões. Certamente essas lesões resultaram da propriedade abrasiva do bicarbonato de sódio. A escovação com agentes abrasivos implica em perda considerável de minerais, uma vez que esses agentes provocam um aumento relevante da rugosidade da superfície do esmalte (HEGEDUS et al., 1999).

Por fim, há de se reconhecer que as lesões produzidas pelos agentes clareadores peróxido de hidrogênio e peróxido de carbamida e pelo abrasivo bicarbonato de sódio têm diferentes graus de severidade. Esse pressuposto 
fundamentado em eletromicrografias que comprovam a gravidade do caráter lesivo das substâncias testadas se constitui numa evidência sustentada em bases metodológicas consistentes.

\section{CONCLUSÃO}

Com base nos resultados da microscopia eletrônica de varredura e considerando os efeitos produzidos sobre a morfologia do esmalte dental humano pelos dentifrícios contendo peróxido de hidrogênio $\left(\mathrm{D}_{1}\right)$, peróxido de carbamida $\left(\mathrm{D}_{2}\right)$ e bicarbonato de sódio $\left(\mathrm{D}_{3}\right)$, pode-se concluir que as ações químicas das substâncias presentes nos dentifrícios $\mathrm{D}_{1}$ e $\mathrm{D}_{2}$, embora tenham eficácia clareadora, produzem lesões com intensidades distintas; que o dentifrício contendo peróxido de carbamida foi o que produziu lesões de menor severidade, enquanto que o creme dental contendo o abrasivo bicarbonato de sódio produziu lesões consideradas de maior gravidade.

\title{
Tooth enamel lesions related to whitening toothpaste
}

\begin{abstract}
Several studies have attributed the appearance of lesions in the enamel morphology after the use of toothwhitening toothpaste. However, there is no consensus among researchers regarding the relevance of the severity of lesions detected on the tooth surface. Objectives: The present study had the aim of evaluating, in vitro, the effects of the hydrogen peroxide, carbamide peroxide and sodium bicarbonate contained in dentifrice formulations, on human tooth enamel. Method and materials: After darkening process in laboratory, human premolars were brushed using dentifrice containing the two whitening substances and the abrasive product. The degree of specimen staining before and after this procedure was determined using spectrophotometry. Scanning electron microscopy (SEM) was used to obtain images, which were analyzed to show the nature of the lesions that appeared on the enamel surface. Results: The effectiveness of the whitening caused by hydrogen peroxide and carbamide peroxide and the abrasion caused by bicarbonate were confirmed, given that the treated test pieces returned to their original coloration. Based on SEM, evaluation of the enamel surfaces subjected to the test products showed that different types of morphological lesions of varying severity appeared. Conclusions: Whitening dentifrice containing hydrogen peroxide and carbamide peroxide produced lesions on the enamel surface such that the greatest sequelae were associated with exposure to hydrogen peroxide.
\end{abstract}

Keywords: Tooth whitening - Whitening dentifrice - Enamel lesions - Hydrogen peroxide - Hydrogen peroxide - Sodium bicarbonate.

\section{REFERÊNCIAS}

1. Araújo, R. M.; Torres, C. R. G.; Araújo, M. A. M. Influência dos agentes clareadores e um refrigerante a base de cola na microdureza do esmalte dental e a ação da saliva na superfície tratada. Revista Odonto Ciência, Porto Alegre, v.21, n.52, p.118-124, 2006.

2. Basting, R. T. Peróxido de Carbamida: Efeitos na micromorfologia e rugosidade das estruturas dentais. Arquivos em Odontologia, Belo Horizonte, v. 41, n. 1, p. 21-27, 2005.
3. Bentley, E. M.; Ellwood, R.P.; Davies, R. M. Fluoride ingestion from toothpaste by young children. British Dental Journal, Londres, v. 186, n. 9, p. 460-462, 1999.

4. Cimilli, H.; Pameijer, C. H. Effect of carbamide peroxide bleaching agents on the physical properties and chemical composition of enamel. American Journal of Dentistry, Weston, Flórida, v. 14, n. 2, p. 63-66, 2001.

5. Cobankara, F. K. Effect of home bleaching agents on the roughnesse and surface morphology of human enamel and dentine. 
International Dental Journal, Genebra, v. 54, n. 4, p. 211-218, 2004.

6. Dietschi, D.; Rossier. S.; Krejci, I. In vitro colorimetric evaluation of the efficacy of various bleaching methods and products. Quintessence International, Illinois, v. 37, n. 7, p. 515-526, 2006.

7. Faraoni-Romano, J. J.; Turssi, C. P.; Serra, M. C. Concentration-dependent effect of bleaching agents on microhardnesse and roughnesse of enamel and dentin. American Journal of Dentistry, Weston, Flórida, v. 20, p. 1, p. 31-34, 2007.

8. FDA. US Food and Drug Admnistration. 2007. Disponível em: <http://www.fda.gov>. $11 / 08 / 2007$

9. Ferreira Zandoná, A. G.; Analoui, M.; Beiswanger, B. B. An in vitro comparison between laser fluorescence and visual examination for detection of demineralization in oclusal pits and fissures. Caries Research, v. 32, n. 3, p. 210-218, 1998.

10. Freitas, P.M.; Basting, R.T.; Rodrigues, J. A.; Serra, M.C. Effects of two $10 \%$ peroxide carbamide bleaching agents on dentin microhardness at different time intervals. Quintessence International, Illinois, v. 33, n. 5, p. $370-375,2002$.

11. Fu, B.; Hoth-Hanning, W.; Hanning, M. Effects of dental bleaching on micro and nanomorphological alterations of the enamel surface. American Journal of Dentistry, Weston, Flórida, v. 20 , n. 1, p. 35-40, 2007.

12. Fugaro, J. O.; Nordahl, I.; Fugaro, O. J.; Matis, B. A.; Mjör, I. A. Pulp reaction to vital bleaching. Operative Dentistry, Indianapolis , v. 29, n, 4, p. 363-368, 2004.

13. Gomes, L. O. Avaliação de alterações cromáticas do esmalte bovino submetido a procedimento de clareamento dental após descolagem de bráquetes ortodônticos. 2005. Thesis (Masters) - School of Dentistry, Federal University of Bahia (UFBA).

14. Goo, D .H.; Kwon, T. Y.; Nam, S. H.; Kim, H. J.; Kim, K. H.; Kim, Y. J. The efficiency of
$10 \%$ carbamide peroxide gel on dental enamel. Dental Materials Journal, Manchester , v. 23, n. 4, p. 522-527, 2004.

15. Hegedus, C.; Bistey, T.; Flora-Nagy, E.; Keszthelyi, G.; Jenei, A. An atomic force microscopy study on the effect of bleaching agents on enamel surface. Journal of Dentistry, Birmingham , v. 27, n. 7, p. 509-515, 1999.

16. Hugo, F. N.; Souza, M. A. L.; Corso, A. C.; Padilha, D. M. P. Efeito erosivo in vitro de um vinho tinto brasileiro sobre esmalte dental bovino observado em microscopia eletrônica de varredura. Revista Odonto Ciência, Porto Alegre, v. 21, n. 51, p.71-75, 2006.

17. Kuz'mina, E. M.; Krikheli, N. I.; Smirnova, T. A. Clinical and laboratory evidence of whitening toothpastes. Stomatologia, Moscou, v. 85, p. 5, p. 13-16, 2006.

18. Lima, M. J. P.; Araújo, R. P. C. Estudo in vitro da ação clareadora do peróxido de hidrogênio a 35\%. Revista Odonto Ciência, Porto alegre, v. 21, n. 54, p. 376-386, 2006.

19. Lizarelli, R. F. Z. Clareamento Caseiro. Revista Gaúcha de Odontologia, Porto Alegre, v. 42, n. 5, p. 275-278, 1994.

20. Lizarelli, Z. F. R.; Moriyama, T. L.; Bagnato, S. V. A nonvital tooth bleaching technique with laser and LED. Journal of Oral Laser Applications, Londres, v. 2, n. 1, p. 45-49, 2002.

21. Miranda, C. B.; Pagani, C.; Benetti, A. R.; Matuda, F. S. Evaluation of the bleached human enamel by scanning electron microscopy. Journal of Applied Oral Science, Bauru, São Paulo, v. 13, n. 2, p. 204-211, 2005.

22. Neves, A. A.; Castro, R. A.; Coutinho, E. T.; Primo, L. G. Microstrutural analysis of demineralized primary enamel after in vitro toothbrushing. Pesquisa Odontológica Brasileira, São Paulo, v. 16, n. 2, p. 137-143, 2002.

23. Nour El-din, A. K.; Miller, B. H.; Griggs, J. A.; Wakefield, C. Immediate bonding to bleached enamel. Operative Dentistry, Indianapolis , v. 31, n. 1, p. 106-114, 2006. 
24. Pasquini, E. E. G. Clareamento em dentes vitais x estruturas dentais. 2006. Disponível em: <ht tp://www.odontologia.com.br/ artigos.asp?id=106>25/03/2009

25. Pinto, C. F.; Giannini, M.; Cavalli, V.; Oliveira, R. Peroxide bleaching agent effects on enamel surface microhardness, roughness and morphology. Brazilian Oral Research, São Paulo, v. 18 , n. 4, p. 306-311, 2004

26. Ribeiro, J. R. A.; Moysés, M. R.; Dias, S. C.; Gomes, P. N.; Reis, A. C.; Ribeiro, J. G. R. Avaliação do $\mathrm{pH}$ dos agentes clareadores. Arquivos em Odontologia, Belo Horizonte, v. 42, n. 1, p. 33-39, 2006.

27. Spalding, M. Estudo in vitro do aspecto morfológico da superfície do esmalte e a alteração na permeabilidade dentária após clareação. 2000. Thesis (Masters) - School of Dentistry, University of São Paulo (USP).

28. Tachibana, T. Y.; Braga, S. E. M; Sobral, M. A. P. Ação dos dentifrícios sobre a estrutura dental após imersão em bebida ácida. Ciência Odontológica Brasileira, São José dos Campos, v. 9, n. 2, p. 48-55, 2006.

29. Watanabe, M. M.; Rodrigues, J. A.; Marchi, G. M; Ambrosano, G. M. B. In Vitro cariostatic effect of withening toothpastes in human dental enamel: microhardness evaluation. Quintessence International, Illinois, v. 36, n. 6, p. 467-473, 2005.

30. White, J. M.; Pelino, J.; Rodrigues, R.; Zwhalen, B. J.; Nguyen, M. H.; Wu, E. Surface and pulpal temperature comparison of tooth whitening using lasers and curing lights. Proc. SPIE., San Francisco , v. 1, n. 4, p. 95-101, 2000 .

31. Wiegand, A; Otto, Y. A.; Attin, T. In vitro evaluation of toothbrushing abrasion of differently bleached bovine enamel. American Journal of Dentistry, Weston, Flórida, v. 17, n. 6, p. 412-416, 2004.

32. Worschech, C. C.; Rodrigues, J. A.; Martins, L. R. M.; Ambrosano, g. M. B. In vitro evaluation of human dental enamel surface roughnesse bleached with 35\% carbamide peroxide and submitted to abrasive dentifrice brushing. Pesquisa Odontológica Brasileira, São Paulo, v. 17, n. 4, p. 342-348, 2003.

33. Worschech, C. C.; Rodrigues, J. A.; Martins, L. R. M.; Ambrosano, g. M. B. Brushing effect of abrasive dentifricies during at-home bleaching with $10 \%$ carbamide peroxide on enamel surface roughness. Journal of Contemporary Dental Practice, Cincinnati, Ohio, v. 7, n. 1, p. 2534, 2006. 